\title{
Intervención grupal psicoeducativa y de apoyo emocional en personal del Instituto Nacional de Pediatría, posterior al sismo del 19 de septiembre de 2017
}

\section{Psychoeducation and emotional support group intervention in Instituto Nacional de Pediatría personnel, after the earthquake on September $19^{\text {th }}$ of 2017.}

Cointa Arroyo-Jiménez, ${ }^{1}$ Sergio Ignacio Muñoz-Fernández, ${ }^{2}$ Lucía Aurora Torres-Pérez, ${ }^{3}$ Argelia Lara-Puente, ${ }^{4}$ Oscar Sánchez-Guerrero, ${ }^{4}$ María Aldrete-Flores Darán, ${ }^{4}$ María Guadalupe Enríquez-Grimaldo, ${ }^{4}$ Juan Antonio Esquivel-Acevedo, ${ }^{4}$ María Juana Piña-Ramírez ${ }^{4}$

\begin{abstract}
Resumen
OBJETIVOS: detectar las necesidades emocionales inmediatas del personal de salud del Instituto Nacional de Pediatría derivadas del sismo del 19 de septiembre de 2017 y contribuir a reducir o controlar la aflicción, el sufrimiento, la tristeza y la ansiedad que aparecen como consecuencia del suceso traumático.

MATERIALES Y MÉTODOS: estudio exploratorio, cualitativo y transversal, efectuado en trabajadores del Instituto Nacional de Pediatría mediante siete intervenciones grupales de diferentes áreas del hospital con una duración de 90 minutos en cinco fases descritas en el protocolo de intervención grupal. Los datos se recolectaron en bitácoras escritas y se hizo un análisis cualitativo de frecuencias.

RESULTADOS: participaron 169 trabajadores que expresaron recuerdos vívidos visuales, auditivos, cinestésicos y sensoriales del momento del temblor, en los que percibieron una amenaza grave a su vida, con miedo y angustia. Refirieron conductas de pérdida de control (propias y ajenas) e implementación de medidas de precaución. Días posteriores al sismo tuvieron miedo anticipatorio, modificación de hábitos y propusieron algunas acciones de recuperación.

CONCLUSIÓN: los datos cualitativos obtenidos invitan a dar seguimiento a los grupos de intervención y tomar en cuenta las sugerencias de los distintos tipos de grupos porque es importante proporcionarle el apoyo al personal que labora en esta institución para favorecer la homeostasis y, consecuentemente, el adecuado desempeño de sus labores. PALABRAS CLAVE: salud mental; desastres naturales; terremoto; estrés agudo; intervención en crisis; sistema de soporte psicosocial; educación para la salud.
\end{abstract}

\section{Abstract}

OBJECTIVE: To detect immediate emotional needs in Instituto Nacional de Pediatría health personnel derived from the September 19th, 2017 earthquake, and contribute to reduce or control affliction, suffering, sadness and anxiety that appeared as a consequence of this traumatic event, and identify those in need of specialized intervention and refer them to corresponding services.

MATERIALS AND METHODS: This is an exploratory, qualitative and cross-sectional study, in which seven group interventions were performed in different hospital services. The group intervention was held in 90 minutes, trough five stages described in the protocol. Data collection was done by means of written reports and a frequency qualitative analysis was made.

RESULTS: Participants expressed having vivid visual, auditive, kinestesic and sensorial memories about the earthquake, having perceived a serious threat to their lives; they also experienced fear and anxiety. They reported loss of control behaviors in themsel-
${ }^{1}$ Psicóloga clínica especializada, adscrita al servicio de Salud Mental.

${ }^{2}$ Jefe del servicio de Salud Mental.

${ }^{3}$ Investigadora externa.

${ }^{4}$ Adscrito al servicio de Salud Mental.

Instituto Nacional de Pediatría, Ciudad de México.

Recibido: 20 de octubre 2017

Aceptado: 5 de marzo 2018

Correspondencia

Sergio Ignacio Muñoz Fernández

sergiomf535@yahoo.com.mx

Este artículo debe citarse como Arroyo-Jiménez $C$, Muñoz-Fernández SI, Torres-Pérez LA, Lara-Puente A, Sánchez-Guerrero O, Aldrete-Flores Darán $\mathrm{M}$, Enríquez-Grimaldo $\mathrm{MG}$ Esquivel-Acevedo JA, Piña-Ramírez MJ. Intervención grupal psicoeducativa y de apoyo emocional en personal del Instituto Nacional de Pediatría, posterior al sismo del 19 de septiembre de 2017. Acta Pediatr Mex. 2018;39(3):224-243. 
ves and in others, and the implementation of preventive measures. Some days after the earthquake they showed anticipatory fear, habits changes, and proposed some recovery actions.

CONCLUSION: Participants expressed having memories about imminent threat. Qualitative data obtained in this study invite to follow-up the intervention groups, and to consider the different groups suggestions, as it is important to offer emotional support to people working in this Institution, to enhance homeostasis, and thus the optimal performance in their service.

KEY WORDS: Mental Health; natural disasters; earthquake; acute stress; crisis intervention; psychological support system; health education.

\section{ANTECEDENTES}

El 19 de septiembre de 2017, un terremoto con magnitud 7.1 sacudió a seis estados de México, dejando 369 víctimas, ${ }^{1}$ miles de edificaciones dañadas y alteraciones psicológicas en la ciudadanía.

En situaciones de desastre y emergencias complejas se incrementan los signos de sufrimiento psicológico, como la aflicción y el miedo. Se estima que entre una tercera parte y la mitad de la población expuesta (según la magnitud del evento y otros factores) sufre alguna manifestación psicológica, ${ }^{2-4}$ aunque debe destacarse que no todas pueden calificarse como patológicas, la mayor parte debe entenderse como reacciones normales ante situaciones de gran significación o impacto. ${ }^{4}$

Ante los eventos del entorno, el ser humano responde generando un proceso de acomodación, para poder atacar o huir, según sean las condiciones del medio, de la misma manera que lo hacen otros mamíferos. Por lo general, los eventos del entorno son denominados como estrés en un sentido amplio y la respuesta ante éste depende de las características de cada organismo. ${ }^{5,6}$

Cuando ocurre un evento traumático, como un desastre natural, se espera que los mecanismos individuales para afrontar situaciones estresantes se vean rebasados, suscitando reacciones más o menos duraderas ante el estrés agudo, con expresiones corporales o psicológicas que ya no son protectoras, sino que conducen a alteraciones emocionales de gravedad variable. Algunas de las características son: estado de tensión, coloquialmente denominado alerta permanente, síntomas ansiosos, trastornos del sueño, temblores, preocupaciones frecuentes acerca del futuro inmediato (nerviosismo), temor ante lo desconocido y a posibles réplicas, nuevos ritos de organización personal, trastornos del apetito, fatiga, irritabilidad, nerviosismo, angustia, aflicción, revivir el momento traumático, intranquilidad, entre otros. ${ }^{4-7}$

En términos generales, el estado de respuesta aguda al estrés tiene una duración aproximada de cuatro semanas, y desaparece cuando el organismo se adapta nuevamente; sin embargo, en algunos casos el estado de respuesta aguda al estrés deviene en un trastorno por estrés postraumático, cuando los síntomas descritos permanecen y se reviven los hechos traumáticos, volviendo a experimentar las emociones del momento de crisis sin control, de manera tal que se manifiestan estados de ansiedad aguda que generan desadaptación a la vida cotidiana, y este estado de estrés postraumático es lo que genera gran problemática entre los sobrevivientes de estos eventos (aún entre quienes no los vivieron directamente). ${ }^{4-6}$ 
A nivel social hay una tendencia a suponer que quienes tienen datos de ansiedad por los eventos vividos son más débiles o tienen menos fuerza de voluntad que los que pueden resistir tales experiencias. La respuesta ante el estrés está mediada por diversos factores psicológicos, biológicos y de la interacción social, por lo que no es posible saber con certeza si alguien podrá resistir tales eventos hasta que se presentan, y el cómo los va a enfrentar depende de todo lo mencionado. De ahí se desprende la importancia de entender los factores que intervienen y la importancia de la cohesión social, del apoyo entre las personas, para poder reducir la intensidad y la duración de los síntomas descritos. ${ }^{4-6}$

\section{Intervenciones de salud mental}

Durante el periodo de estrés agudo las estrategias de afrontamiento del individuo pueden fallar, dado el estado de sugestionabilidad y vulnerabilidad en el que se encuentra, por lo que la ayuda externa puede ser crítica.?

En las situaciones de crisis, de acuerdo con Slaikeu, existen dos momentos distintos que implican objetivos y estrategias diferentes. Estos pueden ser de primera o segunda instancia. En la primera, en la etapa de estrés agudo, se realizan primeros auxilios psicológicos, enfocados a disminuir el nivel de estrés percibido, así como el peligro de muerte y conductas desadaptativas; proporcionar acompañamiento y vincular a la persona con recursos de ayuda. ${ }^{8}$ La segunda se refiere al proceso terapéutico breve, cuyo objetivo principal es la resolución de la crisis; se enfoca en las estrategias del individuo para asimilar la experiencia e incorporarla a su vida. ${ }^{7}$ Así, el personal de salud mental ayuda a las personas a entender los aspectos de la vida que han cambiado y fomenta el desarrollo de estrategias de afrontamiento y factores protectores para disminuir el riesgo de afectaciones a la salud mental y aumentar la capacidad para sobrellevar la adversidad. 9,10
En un desastre natural, como el sismo experimentado el 19 de septiembre de 2017 en México, se espera que la población presente perturbaciones psicosociales que sobrepasen la capacidad de manejo o afrontamiento. Debido a ello es muy recomendable la formación de grupos como método de intervención. ${ }^{4} \mathrm{~A}$ partir de los sismos de El Salvador y Guatemala, la Organización Panamericana de la Salud (OPS) creó guías de lineamientos para apoyar a la población en materia de salud mental desde el primer momento en que surge una crisis. ${ }^{11}$ Esas guías se han convertido en la pauta a seguir y han sido implementadas por diversos países desde su publicación en el 2002. ${ }^{12}$

La propuesta de la OPS en materia de salud mental brinda herramientas para la evaluación de daños y necesidades de la población durante las primeras 72 horas y durante el mes posterior, así como pautas para la implementación de intervenciones psicológicas, que pueden ser individuales (complementadas con ayuda humanitaria) o grupales. ${ }^{4}$

Las intervenciones grupales tienen mayor alcance en situaciones de desastre, por lo que son una herramienta valiosa en condiciones de esta índole. Los grupos propuestos por la OPS difieren en los propósitos de cada uno; se clasifican en grupos informativos y orientación, que se enmarcarán en las primeras horas; psicoeducativos y de apoyo emocional, que se recomiendan en el periodo inmediato al evento $y$ durante las primeras cuatro semanas, aunque se pueden extender hasta los tres meses siguientes al evento traumático; grupos de ayuda mutua, que pueden continuar como un grupo comunitario; y terapéuticos-servicios especializados en la atención primaria, que pueden ser de mediano y largo plazo. ${ }^{4}$

Dado el propósito de esta intervención, se detallarán los grupos psicoeducativos y de apoyo emocional. El objetivo principal de esta moda- 
lidad consiste en ofrecer apoyo emocional para controlar los efectos psicológicos del suceso. La información específica y dirigida a los intereses del grupo es un objetivo complementario, Por esta razón, el intercambio entre el facilitador y el grupo es bidireccional y favorece la participación de las personas. Al finalizar la intervención grupal, se espera que los participantes puedan volver a sus actividades cotidianas y favorecer el desarrollo de habilidades de afrontamiento para la situación particular en la que viven. Los grupos se integran con personas que comparten problemas o intereses similares derivados de la situación y, eventualmente, puedan coincidir en atributos comunes. Este tipo de grupo se desarrolla en un periodo de hasta tres meses después del suceso, en las semanas posteriores a un desastre se encuentran altos niveles de afectación psicológica. ${ }^{4}$

\section{Intervención grupal psicoeducativa y de apoyo emocional al personal del INP}

El personal de Salud Mental de nuestra institución adaptó el modelo de intervención psicológica grupal de la OPS a las necesidades de apoyo psicológico de los trabajadores y a los recursos disponibles. El resultado fue una intervención grupal de sesión única, en donde se detectaron las necesidades, se brindó psicoeducación sobre estrés agudo y las reacciones que pueden esperarse, además se facilitó un espacio de contención y recuperación emocional. Esta intervención estuvo a cargo de los psiquiatras de niños y adolescentes y psicólogos clínicos adscritos al servicio de Salud Mental de nuestra institución.

En las sesiones impartidas a distintos sectores de trabajadores de nuestra institución también se realizó un tamizaje inicial para detectar a personas que con mayor frecuencia e intensidad tenían manifestaciones psicológicas derivadas de la experiencia traumática, a quienes se les envió a distintas instancias de salud mental. Asimismo, se contempló la posibilidad de integrar grupos terapéuticos con el personal debido a la necesidad surgida.

Como complemento a la sesión de intervención grupal, el servicio de Salud Mental redactó un documento de sugerencias para la recuperación emocional del personal de nuestra institución, siguiendo la pauta de propuestas basadas en evidencias científicas o sugeridas por instancias internacionales ${ }^{13-16}$ (Anexo 1). Además, en atención a la necesidad del personal que tiene a su cuidado niños, también se elaboró una guía de recomendaciones emocionales para menores, igualmente cimentada en evidencia. 4,9,17,18 (Anexo 2).

\section{Planteamiento del problema}

El problema que se detectó posterior al sismo del 19S fue que el personal refería malestar psicológico y físico como consecuencia de emociones y pensamientos difíciles de manejar respecto al sismo, así como la dificultad de continuar asistiendo al trabajo o mantener su rutina cotidiana, por lo que se solicitó apoyo psicológico y orientación.

\section{Justificación del estudio}

La necesidad detectada de orientación y apoyo psicológico para los trabajadores llevó al equipo de salud mental a la creación de un protocolo de acción especializado, para intervenir de forma efectiva e inmediata con las personas del hospital más afectadas y favorecer el restablecimiento del equilibrio emocional del personal como objetivo primario y, de forma secundaria, promover que el Instituto continuara brindando atención eficiente.

\section{OBJETIVOS}

Detectar las necesidades emocionales inmediatas del personal de salud del Instituto Nacional 
de Pediatría derivadas del sismo del 19 de septiembre de 2017 y contribuir a reducir o controlar la aflicción, el sufrimiento, la tristeza y la ansiedad que aparecen como consecuencia del suceso traumático, así como identificar a quienes necesitan intervención especializada y remitirlos a los servicios correspondientes.

\section{MATERIALES Y MÉTODO}

Tipo de estudio

Exploratorio, cualitativo, transversal.

Participantes

Personas que cumplieran los siguientes requisitos:

1. Ser trabajadores del hospital.

2. Participar voluntariamente en los grupos a los que se les invitaba en el horario y la fecha programada.

Se trabajó con una muestra no probabilística. Los jefes de cada área interesada invitaron a los empleados a participar en el grupo de intervención y las personas interesadas se presentaron el día de la sesión grupal de manera voluntaria.

En total se efectuaron siete intervenciones grupales (una por área laboral), a las que asistieron 169 trabajadores de las siguientes áreas del hospital:

- Grupo de la Torre de Investigación: 29 trabajadores.

- Grupo A del Laboratorio de Análisis Clínicos y Estudios Especiales: 22 trabajadores.

- Grupo B del Laboratorio de Análisis Clínicos y Estudios Especiales: 27 trabajadores.

- Grupo de Enfermería: 25 trabajadores.

- Grupo de Banco de sangre: 16 trabajadores.

- Grupo de Terapia Intensiva Neonatal: 18 trabajadores.

- Grupo de Trabajo Social: 32 trabajadores.
Las personas asistieron voluntariamente a los grupos, ninguno se rehusó a participar una vez que ya estaba en el grupo de intervención.

\section{Escenario de trabajo}

Las intervenciones grupales, una para cada área laboral, se llevaron a cabo con los trabajadores, todos adultos jóvenes y mayores, de diferentes profesiones del área médica, de investigación o administrativa. Las intervenciones se realizaron del 29 de septiembre al 20 de octubre del 2017 en las aulas académicas correspondientes de las áreas que participaron en el estudio. A las intervenciones grupales solo acudieron los participantes y los investigadores del estudio.

\section{Recolección de datos}

La intervención grupal duró 90 minutos y se llevó a cabo en cinco fases descritas en el protocolo que puede consultarse en el Anexo 3. Las fases de intervención fueron:

1. Establecimiento del objetivo de la sesión grupal

2. Preguntas exploratorias

3. Psicoeducación acerca del estrés agudo vs estrés postraumático y validación emocional

4. Presentación de acciones de recuperación emocional

5. Detección de casos con necesidad urgente de atención especializada individual y presentación de opciones de canalización.

(Anexo 4)

En la intervención grupal se trabajó con una guía de entrevista estructurada semiabierta, con preguntas formuladas por los autores. Todas las respuestas se registraron en bitácoras escritas que tomaron dos investigadores encargados de esa tarea durante cada sesión, simultáneamente 
el equipo de trabajo estuvo alerta a las manifestaciones emocionales de los participantes y se acercó a ellos ofreciéndoles apoyo, estando pendientes si necesitaban salir o recibir apoyo individual.

\section{Análisis de los datos}

Al concluir las intervenciones, los investigadores analizaron las respuestas, agruparon las similares o que abordaran los mismos temas y crearon categorías, que fueron aprobadas por consenso. Se crearon tantas categorías como fue necesario hasta que no surgieron nuevas variaciones entre las respuestas, de acuerdo con un criterio de saturación acordado por los investigadores. ${ }^{19}$

Después de aprobar las categorías derivadas de los datos generales se obtuvieron las frecuencias de respuestas de cada una. En un cuadro se vaciaron las citas textuales de todas las respuestas de los grupos, las frecuencias obtenidas y, posteriormente, se graficaron los datos para tener una mejor representación visual de la información. Para efectos de la presentación de los resultados en este artículo y por limitación de espacio, se utilizó un cuadro resumido, que no incluye todas las respuestas de los participantes, pero sí ejemplos de respuestas para cada categoría.

Finalmente se presenta una descripción de los resultados y algunas representaciones gráficas.

\section{RESULTADOS}

En general, los grupos se mostraron participativos, frecuentemente levantando la mano para hablar y compartir su experiencia o responder preguntas. Durante las sesiones algunos participantes lloraron al recordar y narrar experiencias y fue posible darles contención adecuada; se mostraron abiertos a las recomendaciones de recuperación emocional y aportaron otras sugerencias o ejemplos sumados a lo que se proponían.

Algunos se acercaron al final de la sesión con los psicólogos o psiquiatras del grupo y solicitaron información acerca del apoyo especializado por considerar que lo requerían. Asimismo, el grupo de psicólogos y psiquiatras estuvo atento a las reacciones emocionales y las respuestas verbales de los participantes y al detectar casos con mayor riesgo de psicopatología posterior, se sugirió individualmente tomar alguna de las opciones del directorio de instancias de apoyo individual especializado.

Al analizar la información aportada por los participantes, respecto de las preguntas de la primera fase, se obtuvo la frecuencia de respuestas a cada pregunta exploratoria y, a partir de ahí, el porcentaje (Figura 1). Se registraron 448 respuestas que correspondieron al 100\% de las contestaciones, de las que los porcentajes más altos correspondieron a la descripción de experiencias sensoriales en el momento del sismo (19.2\%) y al cambio de conductas y hábitos a partir del desastre (19\%), seguidos de pensamientos durante el evento $(12.6 \%)$, emociones y preocupaciones actuales (10.9\%). El menor porcentaje de respuestas se registró en la descripción de conductas percibidas de sí mismo (3.8\%) y medidas de protección civil (3.8\%). Las respuestas a las preguntas exploratorias se agruparon en categorías y se obtuvo la frecuencia de respuestas a cada categoría (Cuadro 1).

Con respecto a las experiencias sensoriales en el momento del sismo, se observó que los porcentajes más altos de respuestas correspondieron a recuerdos visuales (27\%), auditivos (25\%) y cinestésicos (21\%) de peligro o amenaza. (Figura 2)

En cuanto a las experiencias emocionales los participantes reportaron, principalmente, an- 
Cuadro 1. Categorización de la información brindada por los participantes respecto a las preguntas de la fase 1 (continúa en la siguiente página)

\begin{tabular}{|c|c|c|}
\hline Categoría & Ejemplo del tipo de respuestas & $\begin{array}{l}\text { Frecuencias } \\
\text { totales }\end{array}$ \\
\hline \multicolumn{3}{|l|}{ Experiencias sensoriales en el momento del sismo } \\
\hline Recuerdos visuales de dificultad para la evacuación & No se podía abrir la puerta de emergencia & 8 \\
\hline Recuerdos visuales de peligro o amenaza & Vi moverse el edificio & 23 \\
\hline Recuerdos auditivos de peligro o amenaza & $\begin{array}{l}\text { Se escucharon las paredes crujir y las puertas } \\
\text { de abajo se impactaban }\end{array}$ & 22 \\
\hline Recuerdos cinestésicos de peligro o amenaza & Iba corriendo pero me sentía en un barco & 18 \\
\hline Disociación & Cuando me di cuenta ya estaba en Insurgentes & 10 \\
\hline Síntomas físicos & El día del temblor me sentía tenso & 5 \\
\hline \multicolumn{3}{|l|}{ Emociones experimentadas } \\
\hline Miedo & $\begin{array}{l}\text { Uno de mis temores era morir, y que no me } \\
\text { encontraran y que mi familia estuviera preocupada }\end{array}$ & 7 \\
\hline Angustia & Sentí angustia de no saber cómo estaba mi familia & 8 \\
\hline Otras & No estaba asustado & 10 \\
\hline \multicolumn{3}{|l|}{ Pensamientos durante el evento } \\
\hline Pensamientos catastróficos y resignación a la muerte & Pensé en una réplica y tuve miedo de morir & 14 \\
\hline Recuerdos del temblor de 1985 y otros temblores & Pensé en otro 85 & 9 \\
\hline $\begin{array}{l}\text { Pensamientos relacionados con la familia o } \\
\text { seres queridos }\end{array}$ & $\begin{array}{l}\text { Sonó el teléfono y era mi hijo y se me quitó } \\
\text { un peso de encima }\end{array}$ & 30 \\
\hline Impotencia por no poder ayudar a otros & $\begin{array}{c}\text { Sentí impotencia, yo quería ayudar esa semana, pero } \\
\text { no estaba cerca, tengo una hija y no se me facilitaba, } \\
\text { encontré otras formas de ayudar }\end{array}$ & 3 \\
\hline \multicolumn{3}{|l|}{ Conductas percibidas de los demás } \\
\hline Pérdida de control & $\begin{array}{c}\text { Parecía histeria colectiva y había mucha } \\
\text { desorganización }\end{array}$ & 19 \\
\hline Unión familiar & Me tocó ver a las mamás preocupadas por sus hijos & 3 \\
\hline \multicolumn{3}{|l|}{ Conductas percibidas de sí mismo } \\
\hline Pérdida de control & $\begin{array}{l}\text { Cuando terminó el temblor una compañera } \\
\text { me trató de tranquilizar }\end{array}$ & 11 \\
\hline Conductas religiosas & Empecé a rezar & 6 \\
\hline \multicolumn{3}{|l|}{ Medidas de protección civil } \\
\hline Eficientes & Yo siento que actuamos adecuadamente en el sismo & 14 \\
\hline Ineficientes & $\begin{array}{l}\text { Me sorprendió que no supieran responder, a pesar } \\
\text { de todos los simulacros }\end{array}$ & 3 \\
\hline \multicolumn{3}{|l|}{ Acciones eficientes e inmediatas } \\
\hline Poner a salvo & Afuera ayudé a una doctora que no podía bajar & 20 \\
\hline Contención emocional & $\begin{array}{l}\text { Nos agarramos los tres compañeros, } \\
\text { no podíamos salir }\end{array}$ & 8 \\
\hline Comunicación & Traté de comunicarme con mis hijos & 4 \\
\hline
\end{tabular}


Arroyo-Jiménez C et al. Intervención grupal en personal del INP posterior al sismo del 19S

Cuadro 1. Categorización de la información brindada por los participantes respecto a las preguntas de la fase 1 (continuación)

\begin{tabular}{|c|c|c|}
\hline Categoría & Ejemplo del tipo de respuestas & $\begin{array}{l}\text { Frecuencias } \\
\text { totales }\end{array}$ \\
\hline \multicolumn{3}{|l|}{ Pensamientos, emociones y preocupaciones actuales } \\
\hline $\begin{array}{l}\text { Temor anticipatorio respecto a réplicas o nuevos } \\
\text { temblores, seguridad, familia y el futuro }\end{array}$ & $\begin{array}{c}\text { Cuando regresé a trabajar, yo no quería subir } \\
\text { ni entrar al Metro, etc. }\end{array}$ & 31 \\
\hline Percepción cinestésica de peligro o amenaza & $\begin{array}{c}\text { En mi casa sentí que la cama se movía, cualquier } \\
\text { alarma me pone alerta }\end{array}$ & 15 \\
\hline Pensamientos y conductas religiosas & $\begin{array}{c}\text { Por algo estamos aquí, Dios nos dio otra } \\
\text { oportunidad, vivir el día }\end{array}$ & 3 \\
\hline \multicolumn{3}{|l|}{ Cambios de conducta y hábitos a partir del desastre } \\
\hline Medidas preventivas en caso de emergencia & $\begin{array}{c}\text { En casa hicimos una mochila de emergencia, } \\
\text { documentos personales, cobijas }\end{array}$ & 15 \\
\hline Medidas exacerbadas en caso de emergencia & $\begin{array}{l}\text { Ya no escucho tan fuerte el radio para } \\
\text { escuchar la alarma }\end{array}$ & 39 \\
\hline Restablecimiento de la rutina & $\begin{array}{l}\text { Me fui a un viaje ese fin de semana (Oaxaca) } \\
\text { pero ellos lo tomaron con normalidad }\end{array}$ & 2 \\
\hline Brindar información & $\begin{array}{c}\text { En mi casa educamos a mis hijos para que sepan que } \\
\text { seguirá temblando y les damos medidas } \\
\text { de seguridad, la alarma está enfrente de la casa } \\
\text { y ya damos prevención a los niños }\end{array}$ & 7 \\
\hline $\begin{array}{l}\text { Síntomas de estrés agudo (sueño, actividad, estrés, } \\
\text { miedo, confusión) }\end{array}$ & Al dormir tengo pesadillas: que el edificio se cae & 20 \\
\hline Acciones para ayudar a otros & Hice acopio en casa con los vecinos & 2 \\
\hline \multicolumn{3}{|l|}{ Propuestas de acciones de recuperación emocional } \\
\hline Actividades físicas & Hacer ejercicio & 13 \\
\hline Actividades mentales & Entrenamiento de atención plena & 21 \\
\hline Actividades recreativas & Manualidades, tejer, hacer cosas que me distraigan & 7 \\
\hline Expresiones emocionales & Llorar & 12 \\
\hline Situaciones laborales & Estar en el trabajo & 6 \\
\hline
\end{tabular}

gustia (32\%), miedo (28\%), y otras $(40 \%)$ como indiferencia, impotencia, alegría y tranquilidad.

Por lo que se refiere a los pensamientos durante el evento en las primeras 72 horas, los resultados arrojaron que $54 \%$ de las personas tuvieron pensamientos con respecto a la familia o seres queridos, y otro porcentaje alto tuvo pensamientos catastróficos y de resignación a la muerte (25\%) (Figura 3).

Al hablar acerca de las conductas percibidas por los demás, la mayoría de los participantes describió acciones de pérdida de control (86\%) y en menor medida comportamientos de unión familiar (14\%). Las respuestas recibidas a la pregunta acerca de conductas percibidas de sí mismo fueron también en su mayoría de pérdida de control (65\%) y en menor medida comportamientos religiosos (35\%).

En cuanto a las medidas de protección civil, se encontró que la mayoría de los participantes hablaron de haber realizado y observado medidas eficientes (82\%) más que ineficientes (18\%). 


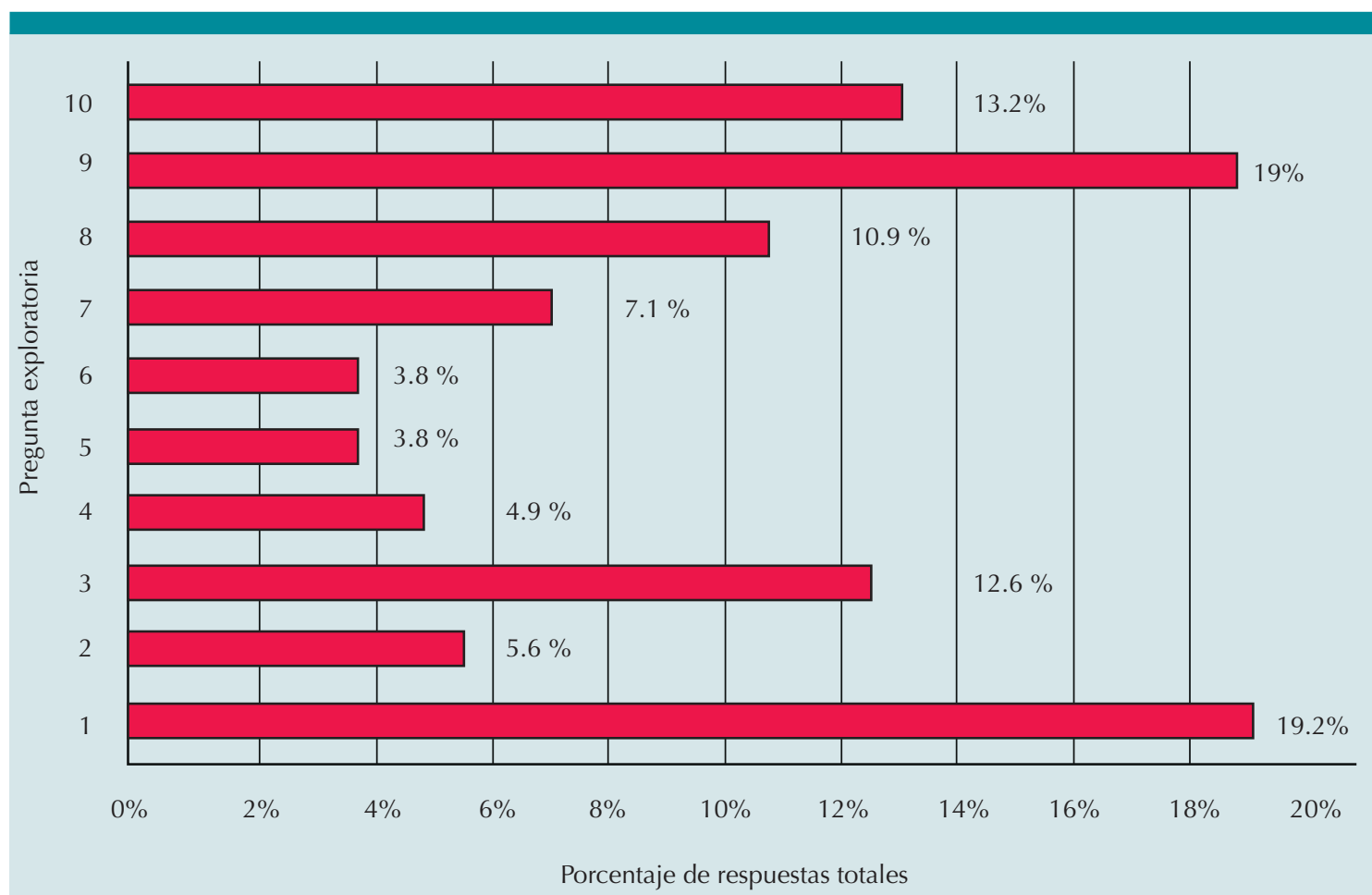

1. Experiencias sensoriales del sismo

2. Emociones experimentadas

3. Pensamientos durante el evento y primeras 72 horas

4. Conductas percibidas de los demás

5. Conductas percibidas de sí mismo
6. Medidas de protección civil

7. Acciones eficientes e inmediatas

8. Pensamientos, emociones y preocupaciones actuales

9. Cambio de conducta y hábitos a partir del desastre

10. Propuestas de acciones de recuperación emocional

Figura 1. Porcentaje de respuestas a cada pregunta exploratoria de la fase 1.

Al preguntar acerca de las acciones tomadas durante e inmediatamente después del sismo, lo reportado indica que la mayoría hizo cosas para ponerse a salvo $(62 \%)$ y en menor medida para contener emocionalmente a los demás (25\%) (Figura 4).

Con respecto a los pensamientos, emociones y preocupaciones actuales de las personas, la mayoría habló de temor anticipatorio con respecto a réplicas o nuevos temblores, seguridad, familia y el futuro (Figura 5).

En relación con el cambio de conductas y hábitos a partir del desastre, se encontró que $46 \%$ de las personas describieron haber tomado medidas exacerbadas en caso de emergencia vs medidas preventivas adecuadas (18\%); el $24 \%$ de las personas refirieron haber experimentados síntomas de estrés agudo. (Figura 6)

Por último, respecto de las propuestas de acciones de recuperación emocional, la mayoría sugirió actividades mentales (35.6\%) seguidas de actividades físicas $(22 \%)$ y de expresión emocional (20.33\%). En menor porcentaje las personas hablaron de recurrir a actividades recreativas (11.9\%) o de regresar al trabajo (10.17\%), como opciones de recuperación emocional. 


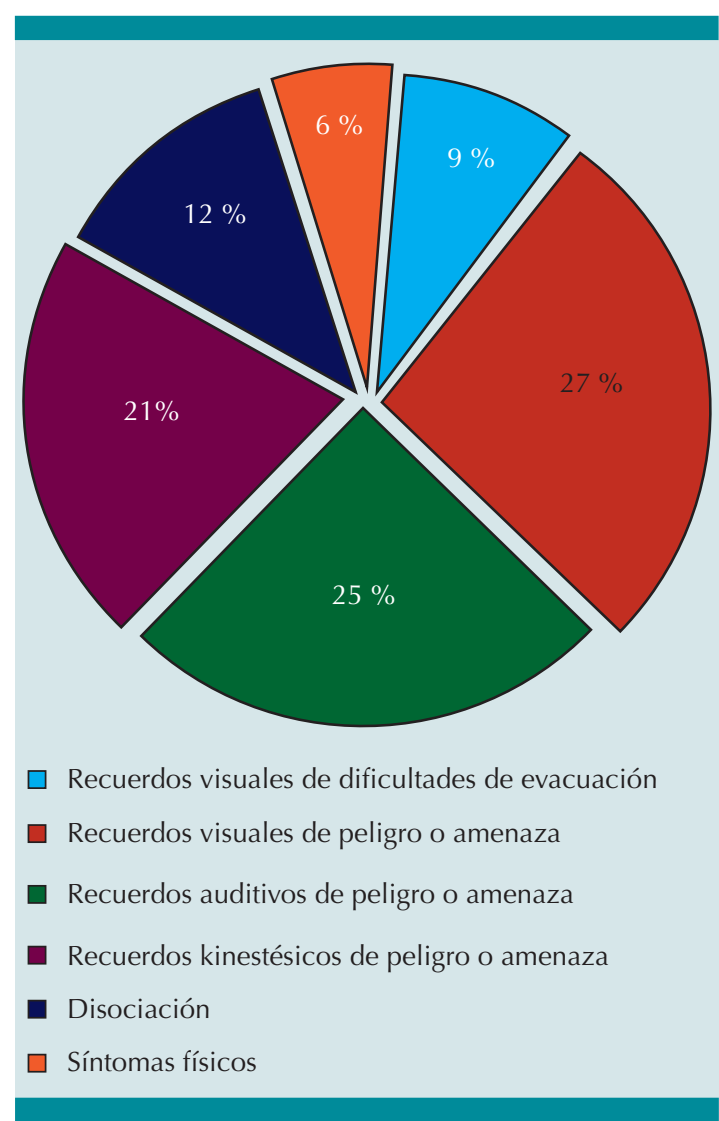

Figura 2. Subcategorías de experiencias sensoriales en el momento del sismo.

El $16.5 \%$ del total de participantes fueron referidos a intervención especializada porque manifestaron la necesidad de contar apoyo individual, entregándoles un listado de instancias de apoyo psicológico para continuar con su atención.

\section{DISCUSIÓN}

Previo a que el equipo de salud mental implementara las intervenciones grupales de apoyo en la institución, se encontraron, a nivel anecdótico, signos de alarma observados y reportados por los jefes de distintas áreas, quienes advirtieron la necesidad de intervenir con apoyo emocional y psicoeducación. Los datos observados fueron:

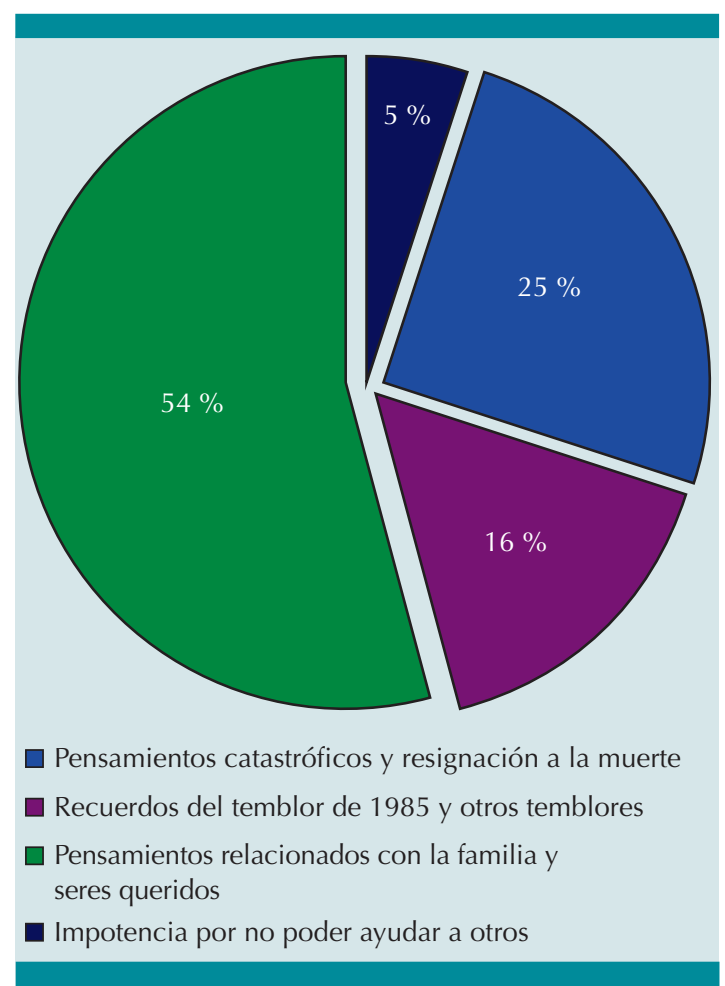

Figura 3. Subcategorías de pensamientos durante el evento y primeras 72 horas.

aflicción, alarma, miedo u otras reacciones emocionales, ausentismo laboral, rumores o información inadecuada acerca de la seguridad del edificio y la creencia de que ocurriría un evento sísmico de mayor magnitud en el corto plazo.

En esta investigación exploratoria se encontraron datos relevantes que permitieron comprender la forma en que muchos de los trabajadores de la institución vivieron el pasado sismo del 19 de septiembre, lo que permitió detectar necesidades específicas de atención y brindar una intervención breve de forma inmediata. Aunque muchas de las reacciones y necesidades habían sido anteriormente descritas, ${ }^{4-7}$ la investigación arrojó datos de una población particular en un contexto y tiempo específico; algunos autores reportan que las respuestas ante una crisis varían según la cultura y el momento. ${ }^{20}$ 


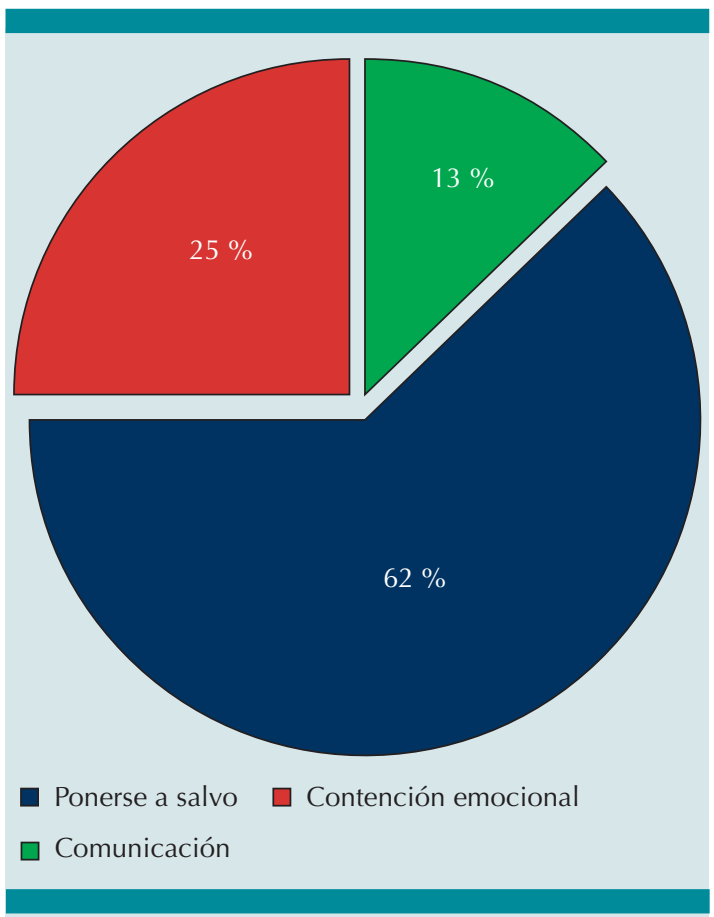

Figura 4. Subcategorías de acciones eficientes e inmediatas.

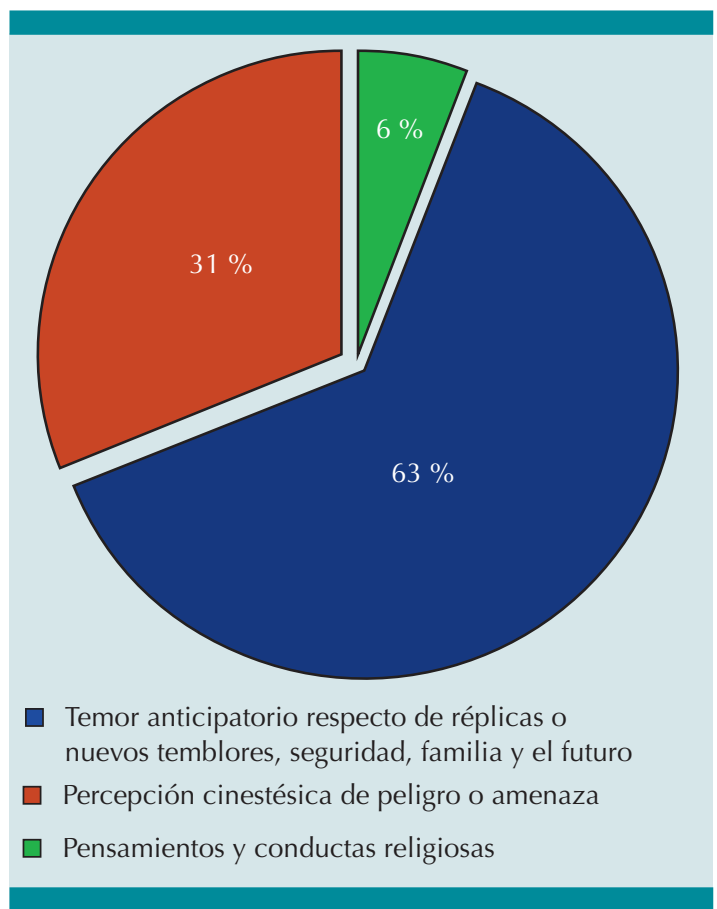

Figura 5. Subcategorías de pensamientos, emociones y preocupaciones actuales.

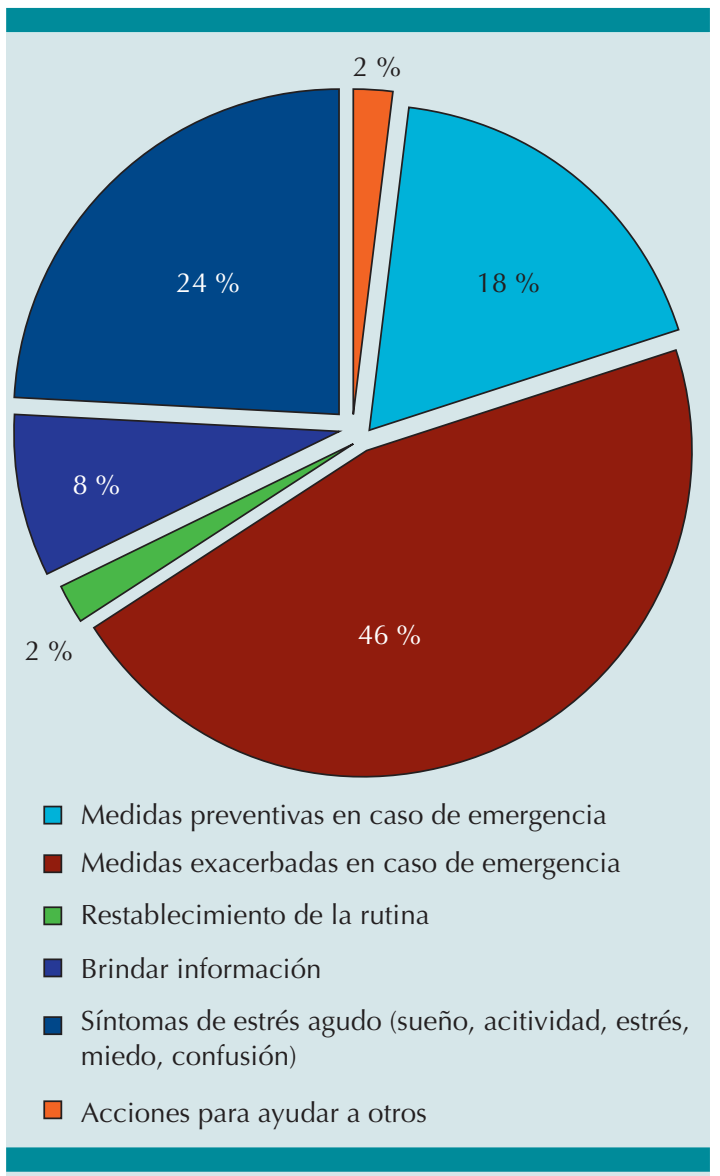

Figura 6. Subcategorías de cambio de conductas y hábitos a partir del desastre.

Resulta interesante que en el momento de las intervenciones grupales las personas hablaron mucho más sobre sensaciones y pensamientos durante el evento, así como de los cambios de conducta y hábitos a partir del desastre derivados de las preocupaciones inmediatas, en comparación con otros temas sugeridos en los grupos, como las medidas de protección civil o las conductas percibidas de sí mismos. Esto plantea tres ideas importantes a tomar en cuenta: la primera consiste en que las personas en este estudio quizá se sintieron motivadas a acudir al grupo porque identificaron una necesidad de contar con un espacio de expresión emocional posterior al sismo. La segunda idea 
contempla la importancia de dar prioridad a la facilitación de espacios para externar emociones y pensamientos de manera inmediata a una crisis. La tercera, consiste en que a partir de los pensamientos, emociones y preocupaciones ante el desastre, la gente realizó cambios de conducta y de hábitos que modificaron su estilo de vida y que probablemente agudizaron los síntomas de estrés, más allá de reducirlos.

Al hablar de lo vivido durante el evento, la mayoría experimentó percepción de peligro y amenaza a la vida, incluso varias personas mencionaron sentirse resignadas a morir justo mientras ocurría el temblor, además de que experimentaron, sobre todo, miedo y angustia a partir de lo que veían, escuchaban y sentían. Esto es consistente con la evidencia previa, que describe que las personas durante una crisis tienen percepciones de transgresión, amenaza y pérdida. ${ }^{21}$ Lo anterior puede relacionarse con que durante el evento y las primeras 72 horas las personas pensaban, principalmente, en sus seres queridos, así como en ideas catastróficas del futuro; incluso, admitieron llevar a cabo conductas religiosas como rezar por ellos y sus familiares, lo que concuerda con estudios que han evaluado la percepción de afectación y amenaza durante una crisis. ${ }^{22}$

En relación con las conductas de la gente durante el evento sísmico, resulta relevante que las personas notaron mayormente la pérdida de control en los demás que en ellos mismos. Esto probablemente se debe a que en situaciones críticas puede resultar más fácil observar el comportamiento de los otros que autobservarse; sin embargo, con todo y esto las personas se notaron y percibieron a los demás eficientes en seguir las medidas de protección civil, quizá porque se había efectuado un simulacro algunas horas antes.

En cuanto a las conductas inmediatas al sismo, $60 \%$ de las personas reportaron hacer cosas con la intención de poner a salvo a otros y ayudar, esto quizá funcionó como una estrategia para afrontar la situación de desastre que se estaba experimentando. En menor medida, pero no menos importante, otros se concentraron en brindar contención emocional a otros, y de esa manera enfrentar la situación.

Al parecer, tiempo después del evento sísmico las personas tuvieron miedo a las réplicas o temblores más fuertes, preocupación por su seguridad, su familia y su futuro, lo que llevó a casi $50 \%$ de las personas a cambiar sus hábitos de vida implementando acciones exacerbadas con la intención de estar más alertas ante la posibilidad de otro evento, como por ejemplo dejar las ventanas abiertas para escuchar la alerta sísmica, dormir con zapatos y no cerrar la puerta con Ilave. Este tipo de reacciones resultan esperadas cuando las personas experimentan síntomas de estrés agudo, ${ }^{23}$ como le sucedió a por lo menos una cuarta parte de los participantes de este estudio.

Por último, ante el desajuste emocional que supuso este desastre natural, las personas sugirieron e implementaron, en su mayoría, actividades mentales para intentar lograr una recuperación emocional y en menor medida, intentaron recuperar el equilibrio por medio de actividad física o de permitirse expresar lo que sentían. Regresar a la rutina de trabajo como sugieren algunos autores $\mathrm{s}^{23} \mathrm{o}$ hacer actividades recreativas fueron las opciones que menos consideraron las personas al pensar en un plan de recuperación emocional, porque varias personas vivieron el sismo en el lugar de trabajo.

Los datos cualitativos obtenidos invitan a dar seguimiento a los grupos de intervención y tomar en cuenta las sugerencias de los distintos tipos de grupos porque es importante proporcionar apoyo al personal que labora en esta institución para favorecer la homeostasis $y$, consecuentemente, el adecuado desempeño de sus labores. 
Nota

Los autores declaran que no tienen ni existe conflicto de interés que hubiera influido en los resultados de este estudio. Asimismo, declaran que no recibieron ningún tipo de financiamiento, pues los gastos del ensayo fueron cubiertos por ellos.

\section{REFERENCIAS}

1. Martínez F. La cifra final de fallecidos en el país llegó a 369. La Jornada [Internet] 2017 Oct 5; Política (p.3). Disponible en: http://www.jornada.unam.mx/2017/10/05/ politica/003n2pol.

2. Cova F, Rincón P. El terremoto y tsunami del 27-F y sus efectos en la salud mental. Ter Psicol. 2010;28(2):179-185.

3. Udomratn P. Mental health and the psychosocial consequences of natural disasters in Asia. Int Rev Psychiatry. 2008;20(5):441-444.

4. Rodríguez J, Davoli Z, Pérez R. Guía práctica de salud mental en situación de desastres. Washington: Organización Panamericana de la Salud, 2006;189.

5. Sánchez O. Trastorno por estrés agudo. En: De la Peña F. Psicopatología básica de niños y adolescentes. México: Asociación Psiquiátrica Mexicana, 2015;457-470.

6. Sánchez O. Trastornos de adaptación. En: De la Peña F. Psicopatología básica de niños y adolescentes. México: Asociación Psiquiátrica Mexicana, 2015;496-507.

7. Slaikeu K. Intervención en crisis. México: El Manual Moderno, 2006;575.

8. Nash WP, Watson PJ. Review of VA/DOD Clinical practice guidelines on management of acute stress and interventions to prevent prostraumatic stress disorder. J Rehabil Res Dev. 2012;49(5):637-348.

9. Powell T, Thompson, S. Enhancing coping and supporting protective factors after a disaster: Findings from a quasi-experimental study. Res Soc Work Pract. 2016;26(5), 539-549.

10. Osorio-Parraguez P, Espinoza A. Salud mental en desastres naturales: estrategias interventivas con adultos mayores en sectores rurales de Chile. Glob Heatlh Promot. 2016; 23(2): 84-91.

11. De Ville de Goyet C. Earthquakes in El Salvador. Rev Panam Salud Pública. 2001;9(2):107-113.
12. Méndez MD, Leiva M C, Bustos C B, Ramos N A, MoyanoDíaz E. Mapa exploratorio de intervenciones psicosociales frente al terremoto del 27 de Febrero de 2010 en la zona centro-sur de Chile. Ter Psicol. 2010;28(2): 193-202.

13. American Psychological Association [Internet] Washington: American Psychological Association 2017. Recovering emotionally from disaster; 2013 Agosto [Citado en 2017 Oct 09]; [3 p.] Disponible en: http://www.apa.org/helpcenter/ recovering-disasters.aspx.

14. World Health Organization, War Trauma Foundation, World Vision International. Psychological first aid: Guide for field workers. Genova: WHO; 2011;64.

15. Xiong P, Yang L, Zhu Z. Relation of postraumatic growth to meaning of life and experiential avoidance in adolescents. Chinese Mental Health Journal. 2014;28:1-7.

16. Dursun P, Steger M, Bentele C, Schulenberg, E. Meaning and posttraumatic growth among survivors of the September 2013 Colorado floods. J. Clin. Psychol. 2016 Dic 1;72(12):1247-1263.

17. France K, Tarren-Sweeney M, Hall S. Tips for coping with distress in Young children after the earthquake [Internet] Christchurch: University of Canterbury [citado en 2017 Oct 09]5 p. Disponible en: https://ir.canterbury.ac.nz/ bitstream/handle/10092/5215/12630286_Children's\%20 stress-final.pdf; sequence $=1$

18. Kinoshita I, Woolley H. Children's Play Environment after a Disaster: The Great East Japan Earthquake. Children. 2015; 2(1):39-62.

19. Mayan M. Essentials of qualitative inquiry. Walnut Creek: Left Coast Press, 2009;172.

20. Dykeman BF. Cultural implications of crisis intervention. Journal of Instructional Psychology. 2005;32(1):45-48.

21. Lazarus, R.S. Why we should think of stress as a subset of emotion. In: L. Goldberger and S. Bresnitz (eds.), 2nd ed. Handbook of stress: Theoretical and clinical aspects. New York: Free Press 1993;21-39.

22. Myer RA, Conte C. Assessment for crisis intervention. Journal of Clinical Psychology: In Session. 2006; 62 (8): 959-970.

23. De la Barra F y Silva H. Desastres y salud mental. Revista Chilena de Neuropsiquiatría. 2010; 48(1):7-10. 


\section{ANEXO 1. SUGERENCIAS DE RECUPERACIÓN EMOCIONAL PARA ADULTOS}

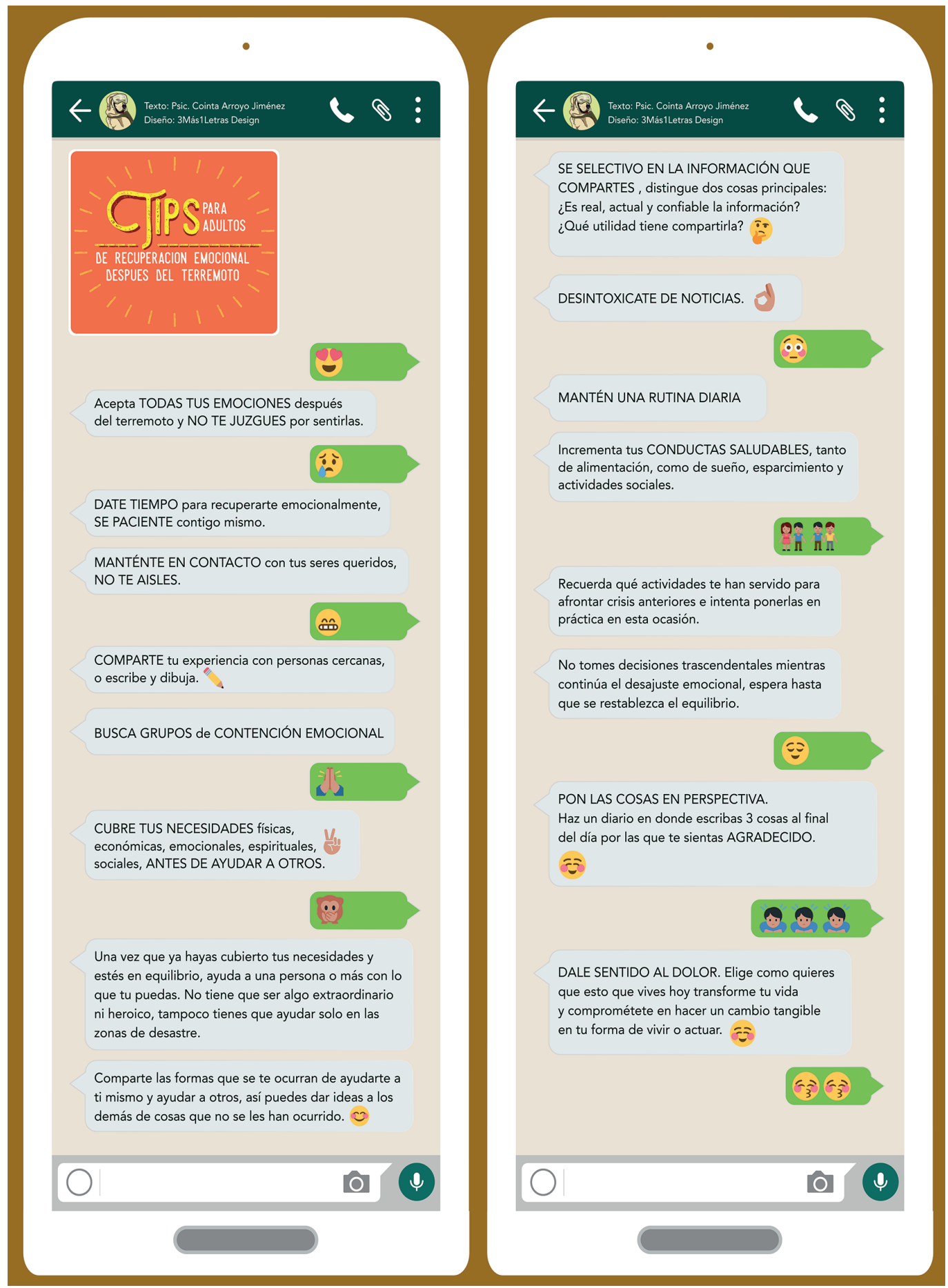




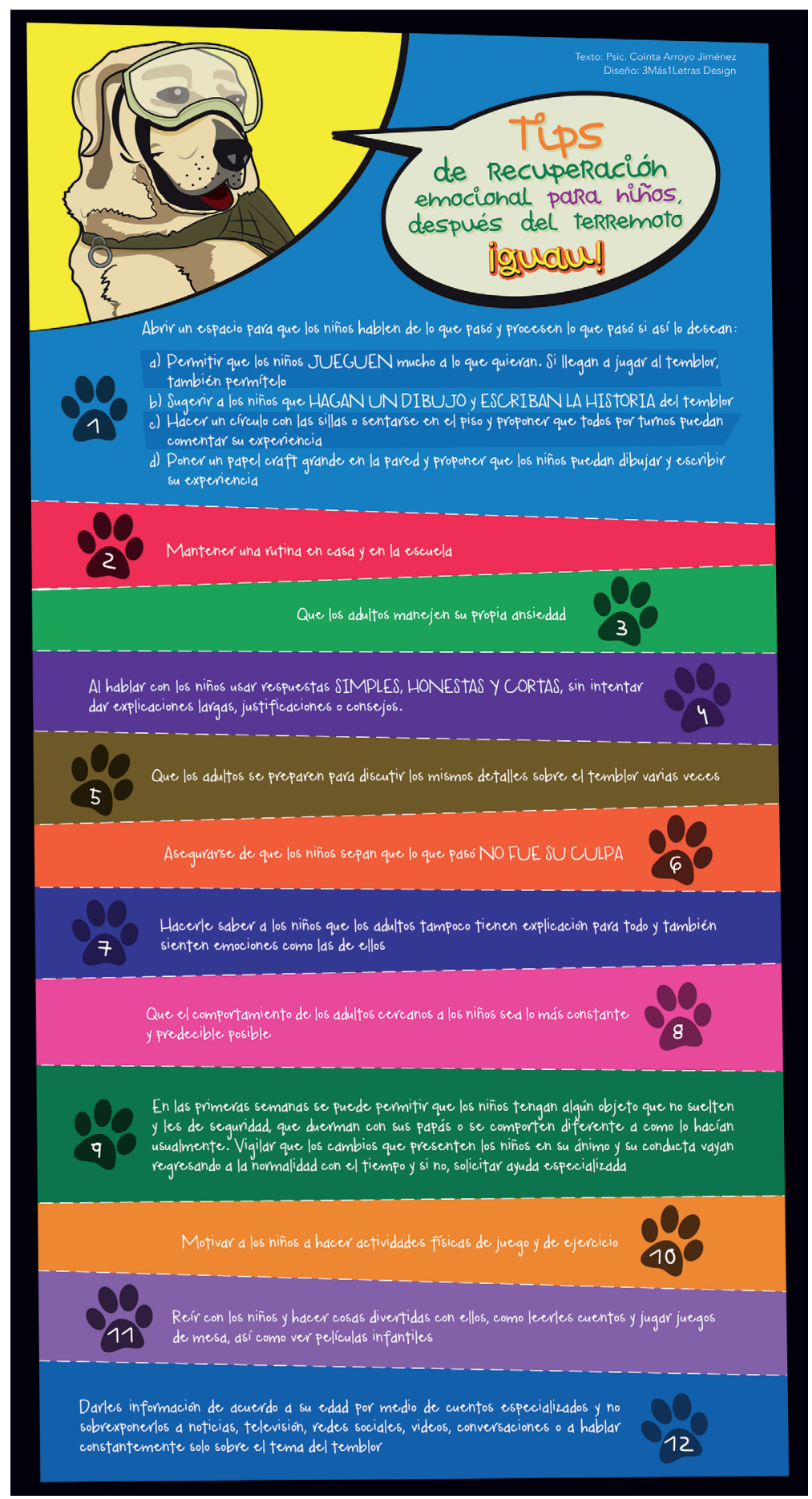




\section{ANEXO 3. PROTOCOLO DE INTERVENCIÓN GRUPAL}

\section{Fases de intervención}

1. Establecer el objetivo de la sesión grupal: Fase a cargo del jefe de servicio de salud mental.

2. Preguntas exploratorias: Dos psicólogas formularon las preguntas que se enlistan más adelante, las cuales fueron previamente establecidas en el protocolo de intervención y motivaron a los participantes a levantar la mano y tomar la palabra, así como a profundizar en sus respuestas.

a. ¿En dónde estaba cuando tembló y qué imágenes recuerda?

b. ¿Qué emociones sentía?

c. ¿Qué pasaba por mi cabeza, qué pensaba?

d. ¿Qué hacían las personas a mi alrededor?

e. ¿Qué hice yo?

f. ¿Qué emociones tengo ahora y después del temblor?

g. ¿Qué pensamientos tengo ahora y después del temblor?

h. ¿Qué es lo que más preocupa en este momento?

i. ¿Qué cosas hago diferentes después del temblor? ¿Qué cambio en mí y en los demás?

j. ¿Qué ideas propongo para ir recomponiendo o curando mi corazón y el de los demás?

3. Brindar psicoeducación y validación emocional: uno de los psiquiatras de niños y adolescentes del equipo dio una breve ex- plicación acerca de las respuestas al estrés agudo esperadas y la diferencia entre estas respuestas y el diagnóstico de estrés postraumático, enfocándose en normalizar las emociones, sensaciones, pensamientos y cambios de conducta a partir del sismo del 19 de Septiembre de 2017.

4. Explicar las acciones de recuperación emocional que el equipo de Salud Mental propone: una de las psicólogas explicó detalladamente los "Tips de recuperación emocional" brindando ejemplos específicos y animando a los participantes a contribuir con ejemplos personales que se relacionara con la información brindada.

5. Detectar casos con necesidad urgente de atención especializada individual y brindar opciones de canalización mediante el directorio de instancias de atención psicológica que se han conformado para esta situación.

Para el cierre se les reconoció a los trabajadores su participación y la importancia de haber compartido su experiencia, además de brindarles por escrito los materiales siguientes:

- Tips de recuperación emocional para adultos (Anexo 1)

- Tips de recuperación emocional para niños (Anexo 2)

Directorio de instancias que brindan atención telefónica, en línea o presencial a personas que presentan síntomas de estrés agudo y dificultad para manejarlos o que posteriormente presenten datos de estrés postraumático o secuelas psicológicas a partir del evento traumático. 


\section{Atención psicológica vía telefónica:}
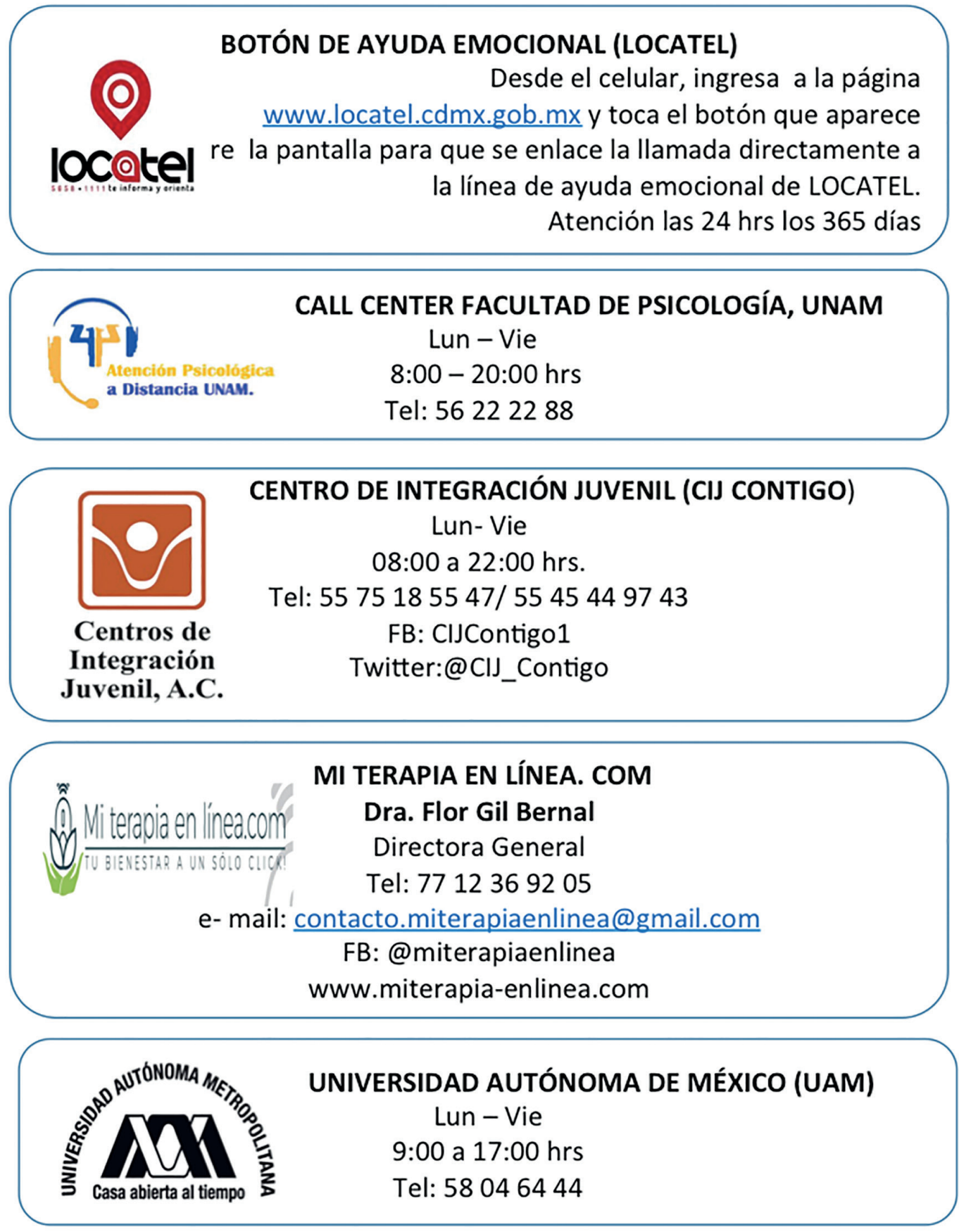


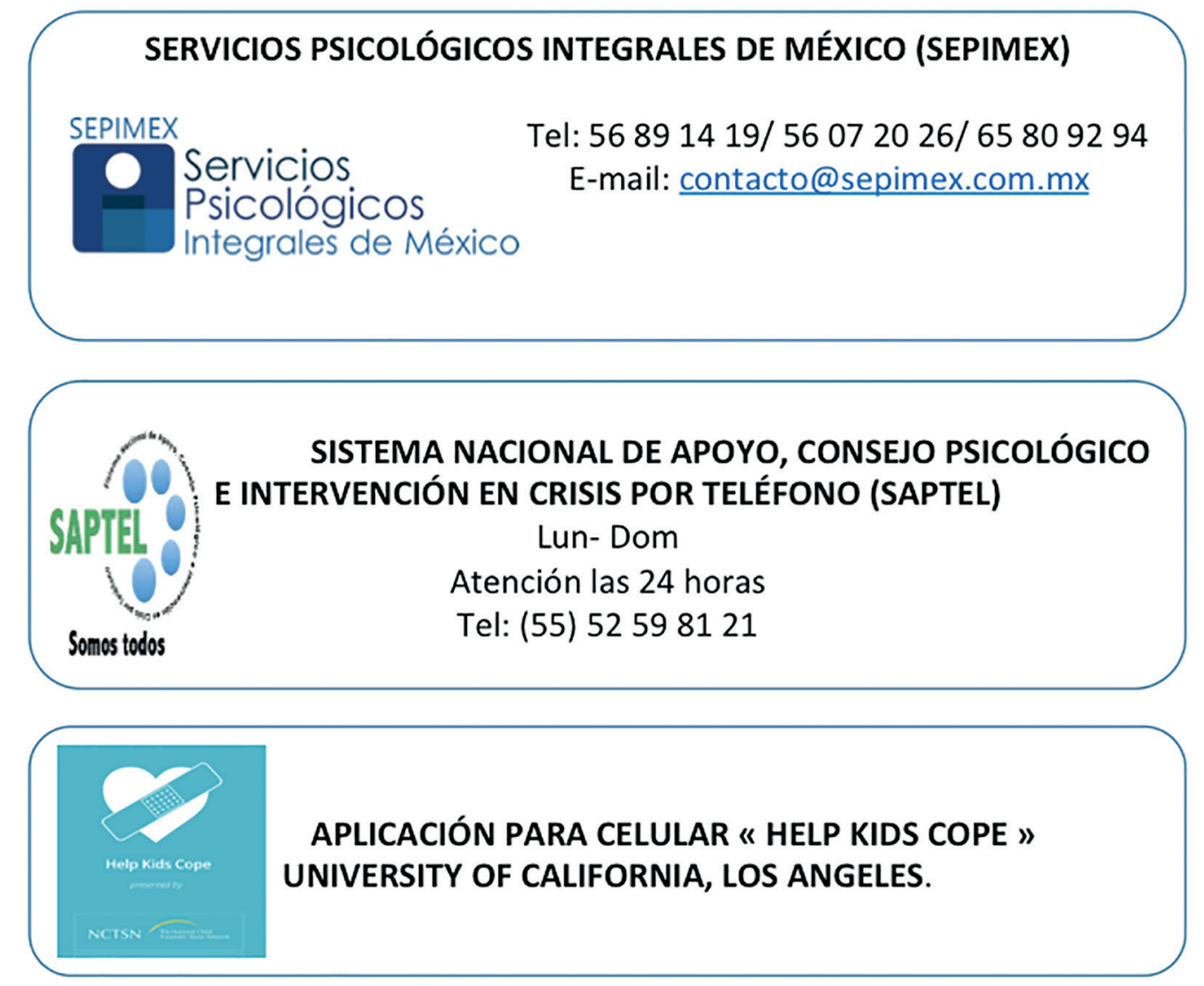

\section{Atención psicológica presencial:}

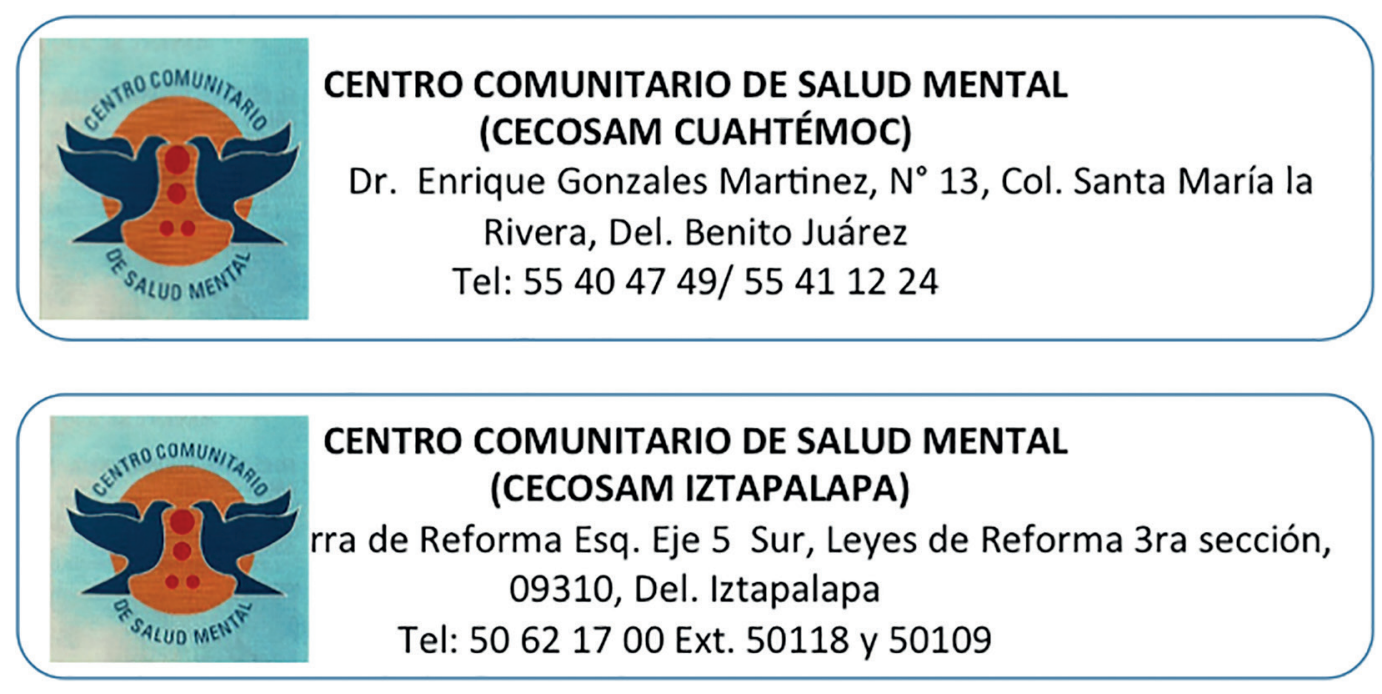



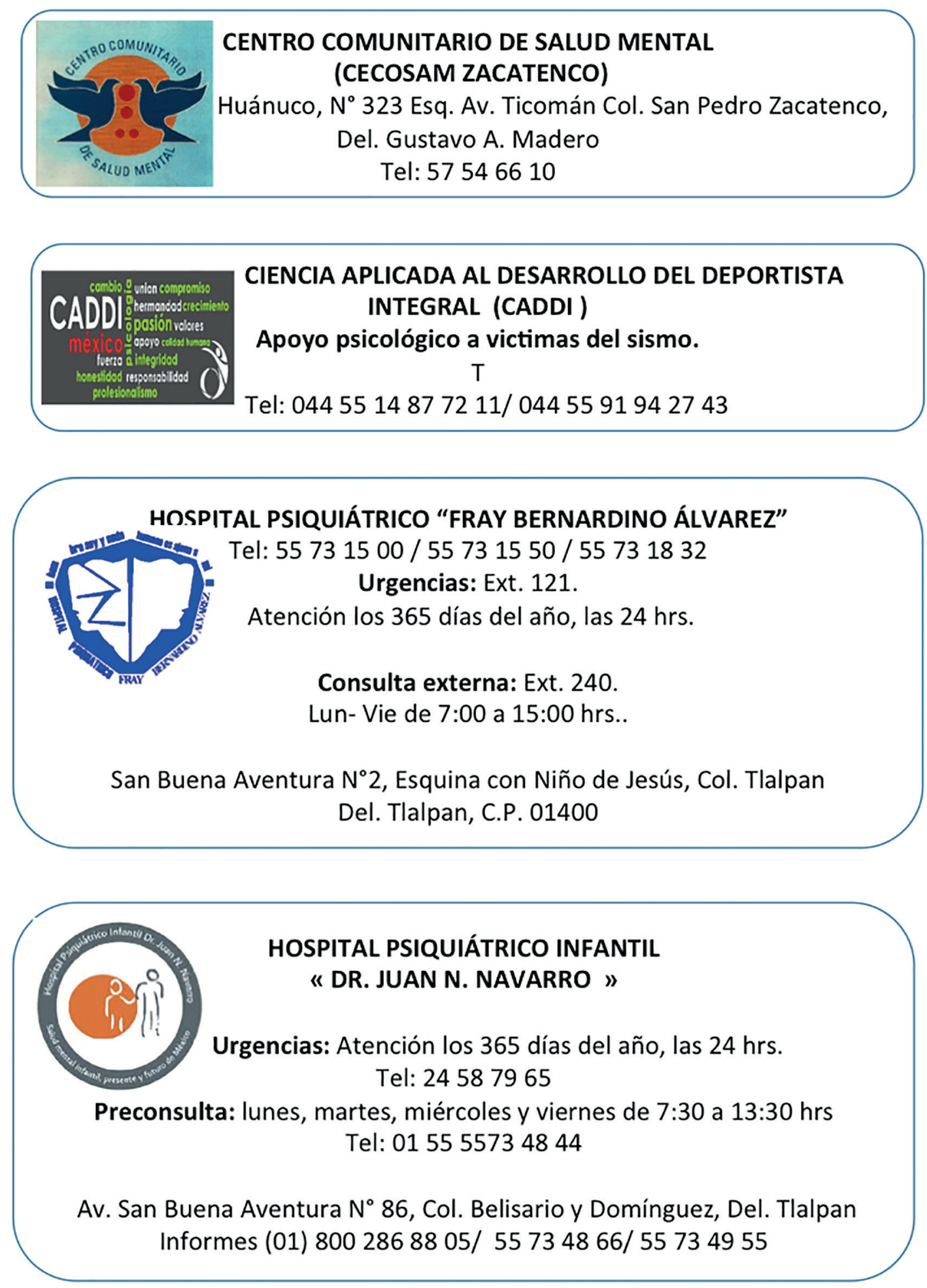


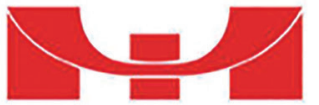

INSTITUTO NACIONAL

DE P S I U I A TR I A Intervención en crisis por el sismo marca al:

RAMON DE LA FUENTE

0180095300 12/018006114488

Cita de primera vez: 41605372

\section{INSTITUTO NACIONAL DE PSIQUIATRÍA}

" RAMÓN DE LA FUENTE MUÑIZ»

Tel: 015541605000

Informes sobre los servicios de atención clínica: 41605504

Calz de México Xochimilco, $N^{\circ} 101$,

Col San Lorenzo Huipulco, C.P. 14370

Del. Tlalpan

\section{LIBER \\ TERAPIA COGNITIVO CONDUCTUAL}

Atención de forma presencial y a distancia

LiBeR

Del 21 de Septiembre al 15 de Octubre del 2017

Tel: 55288648 95/ 55276848 96/5527129973/55 4036 95 70/55

$21143336 / 5538903563 / 5564759690$

FB: facebook.com/LiberTcc. 